\title{
Analysis and countermeasures of salary incentive's status quo in XXX performing arts group
}

\author{
ZHOU xiao-yang ${ }^{1}$;WANG yu-yun ${ }^{2}$ \\ ${ }^{1}$ Hohai University,Nanjing 211100,China \\ ${ }^{2}$ Hohai University,Nanjing 211100,China
}

\begin{abstract}
This paper further research the incentive compensation system of the developing cultural enterprise in the new period, on the basis of the compensation mechanism research about the entertainers of one performing arts group.this article investigate compensation mechanism of the internal group entertainers in the form of a questionnaire. Diagnose the salary system of the performing arts group according to analysis results of the questionnaire. Diagnosis in this paper for the performing arts group in different career development stage of entertainers salary incentive problems also can be used by similar enterprises to related.
\end{abstract}

Keywords:Performing arts group; Entertainers; Questionnaire survey;Salary incentive

\section{Introduction}

The sixth plenary session of the 17 th communist party congress passed some major issue decision. The central committee of the communist party of China decides to reform the cultural system further to promote socialist cultural development boom, which proposes that we should deepen the reform of the state-owned culture units. The reform focuses on the establishment of a modern enterprise system, accelerating reform of the for-profit cultural units and cultivating the qualified market main body. And the core of it is cultural enterprise salary system reform. Based on the investigation within the enterprise of entertainers compensation mechanism, this article diagnoses and analyses its problems, proposes the countermeasure, and serve as a reference for the similar enterprise restructuring.

\section{Problems of Entertainers' Salary Incentive Mechanism}

Leaded correctly and supported strongly by the, the provincial party committee and the provincial government, The performing arts company reforms and competes formally in the market. Its 11 troupes reform whole to be enterprises, replace the status of all the employee, perfect the corporate governance structure according to the requirements of establishing modern enterprise system,and reform the internal mechanism, distribution mechanism of choose and employ persons. The reform fully mobilizes the enthusiasm of creative to give. However, because it involves employees' interests and has no perfect system to guide, the compensation mechanism reform encounters difficulties.

This research object is a performing arts company in jiang-su province, which is expected to issue 120 questionnaires, actually 112 , and recycles 105 . Then eliminate 7 invalid questionnaires. So effective questionnaires are 98 altogether, effective questionnaire recovery rate is $87.5 \%$, which satisfies the basic demands of the questionnaire survey.

\subsection{Design of Research Questionnaire}

That mainly involved in the questionnaire are investigation of the incentive factors, survey of pay structures, survey of pay satisfaction, survey of compensation incentive effect and the effect of the compensation mechanism related investigation. Investigation of the incentive factors: mainly according to temple's incentive model, based on the four incentive factors, analyze entertainers biggest factor. Survey of pay structure: mainly includes entertainers understand group company's compensation system or not. Pay satisfaction survey: includes salary pay satisfaction and company's 
compensation plan (whether or not to adjust compensation policy based on the market situation and the group development). Survey of compensation incentive effect: the salary incentive effect mainly includes the long-term and short-term incentive effect, also includes the company whether there is a perfect long-term incentive mechanism.

\subsection{Results Analysis}

(1) The results of the survey analysis about incentive factors

Through analyzing the survey results about the strength of the employees' motivating factors, In the four incentive factors, $52 \%$ of those surveyed staff think in the process of career development, career development has more influence factors; $32 \%$ of the employees think that in the process of career development, material wealth factors' strength is greater; And the remaining $16 \%$ of employees consider that in the process of career development, job success factors and environmental factors influence more. Those suggest that in career development, more entertainers care about is the enterprise can bring help for their career development. In the investigation about the present situation of entertainers, material wealth is the most urgent improvement factor (69\%), followed by the career development factors (23\%).

(2) The analysis of the survey results about compensation structure

Through analyzing the survey results of the current staff salary structure of the group, it shows that lower satisfaction with groups' employee pay structure, including knowledge and reasonable degree. What's more, the satisfaction of welfare system is very low, yet to be improved. In terms of basic pay salary proportion, only $7.14 \%$ of respondents choose to $50 \%$ $\sim 70 \%$, and the rest of the respondents choose more than $70 \%$. That shows the group pay more attention to the basic wages for staff retention, which has certain rationality, but fixed income in total income proportion is too large which will affect employees' enthusiasm and initiative.

(3)Analysis of survey results about pay satisfaction

By analyzing the survey of employees' pay satisfaction, in general, overall employee pay satisfaction is low, but the external competitive ability of salary is high, which is because the group compensation is in a leading position in the industry, while the internal pay equity is not so good. In the plan of the compensation, the compensation mechanism of group generally are not satisfied, which shows that group's compensation mechanism is not fully following with the market and adjusting the salary strategy according to the benefits.

(4) Analysis of the survey results of salary incentive effect

Through analyzing the survey results of the current staff salary incentive effect of the group, on the whole, the group's overall salary incentive effect is general. And compared with short-term incentive, the long-term incentive needs to strengthen more.

\subsection{Problem Analysis}

Based on the result analysis of questionnaire, evaluate the enterprise existing compensation system, diagnose its problems, specific is as follows:

(1) In the four incentive factors' survey, the results showed in the whole development process of career, the entertainers care more about is what enterprise can bring for their career development, and their most urgent factor is the material wealth, which shows that enterprises pay levels cannot meet the employees' psychological expectations. This may be the result of the particularity of the career, on the other hand may be caused by entertainers' internal pay gap is too large.

(2) About pay structure survey in the group, the results showed that in the group's salary system, basic wages accounted for the proportion of total compensation is big, which embodies the basic wage of employees to retain, but also not conducive to employees enthusiasm and initiative,which the degree of identity from their pay structure to it can reflect; Although the group pay enough 5 insurances for employee according to the legal provisions of the state, but employees are not satisfied with the welfare system still.

(3) About pay satisfaction survey in the group, results show that the entertainers' pay satisfaction is still at the low level. The employee internal fairness of compensation satisfaction is low, which may be caused by the employees does not understand the pay 
structure of the enterprise, while the dissatisfaction with group compensation plan is due to the group update compensation too slow.

(4) About the salary incentive effect investigation, the results show that for the entertainers in the process of its entire professional, overall salary incentive effect is poor, in which the short-term incentive effect is good. This may be because the group's short-term incentives can promote employees' skills and adjust the career planning with the increase of age; while long-term incentive response no obvious change trend and.

\section{Conclusion}

In this article, through analyzing salary survey data of some acting enterprise entertainers, combined with the group's existing compensation mechanisms, mainly obtain the following basic conclusion:

(1) In the whole process of career, what entertainers care about more is the enterprise can bring for their career development, and their most urgent improvement factors is the material wealth, which shows that the enterprise's existing compensation can not meet the employees' psychological expectations; But according to the group's 2011 employees salary survey, it shows that the entertainers average salary is 92000 yuan. This paradox may be caused by the particularity of entertainers industry on the one hand.On the other hand, it may be caused by entertainers internal pay gap is too large.

(2) The group should pay attention to the demand of entertainers. Employees in different periods has different demand, and the needs of different employees at the same time also will be different. Therefore, group should take the diversity of employee needs into account. For the present, early career employees pay more attention to material wealth, so the group needs to combine the demand at each stage and design targeted short-term and long-term incentive mechanism.

(3) Pay more attention to the effect of performance appraisal in the salary incentive mechanism. Entertainers think that the structure of performance appraisal are far relevant with compensation in their whole career development process. The ultimate purpose of performance appraisal is to guide and motivate employees to be responsible and make positive contributions. Further more, make employee behavior conform to the requirements of the enterprise core idea and formed "competition, motivation, elimination" positive working atmosphere in enterprises. While realizing the goal of enterprise management, improve employees' satisfaction and sense of achievement.

(4) Pay attention to the role of long-term incentive. Job-hopping is not only the loss of enterprise human capital, but also will increase the cost of enterprise human resources management. But one way of effectively prevent defections is the function of long-term compensation and raise the cost of turnover. For example, EVA bonus bank or other measures will work.

\section{Prospect}

In this paper, the entertainers' salary incentive problems are analyzed. Researching entertainers' salary incentive problems should pay equal attention to long-term and short-term incentive, analyze the characteristic of entertainers to understand their needs, create conditions to meet the needs of entertainers, use scientific and reasonable performance appraisal system to supervise, and formulate perfect compensation system, so that the work enthusiasm of entertainers will be improved. Finally, realize the goal of the rapid development of cultural industry in our country. Through the questionnaire survey method, this paper introduces a performing arts companies as empirical study model, and puts forward some proposals to entertainers salary incentive. No one compensation model is perfect, in the same way, nor a compensation model is useless.

\section{References}

[1] Jing Jing-jing. The Research of the Salary Encouraging System with the Aim of the Enterprise Value about the Banks on the Market in China [D]. Shan dong: Shan dong university, 2007:19.

[2] $\mathrm{Gu}$ li.Significance of implementing performance appraisal [J]. Petroleum Education, 2010, (3): 
105-106.

[3] Zhang Xue-min. Study on Senior Manager Compensation Mechanism of Chinese Listed Companies Based on EVA [D]. Heilongjiang: Harbin Engineering University, 2006: 29.

[4] Wang Xiao-guang. A Study on Chinese Enterprise Salary and The Impact on Labor Relation [J]. Economic Management, 2007,(21): 6-13.

[5] Wen Kui, Wu Dong-mei. Abnormal incentives of Heterogeneous talent -Beijing high-tech enterprise talent incentive mechanism study [J]. Management World, 2003, (10) : 110-114.

[6] Wu Shao-qi, Chen Qian, Yang Qun-hua. Research on compensation satisfaction of teachers in universities focusing on research $[\mathrm{J}]$. Science Research Management, 2005, (5):152-156.

[7] Huang Deng-shi, Zhou Ying-feng. Theoretical and empirical study on EVA: Review and prospect[J]. Journal of Management Sciences in China, 2004, (1) : 80-87. 